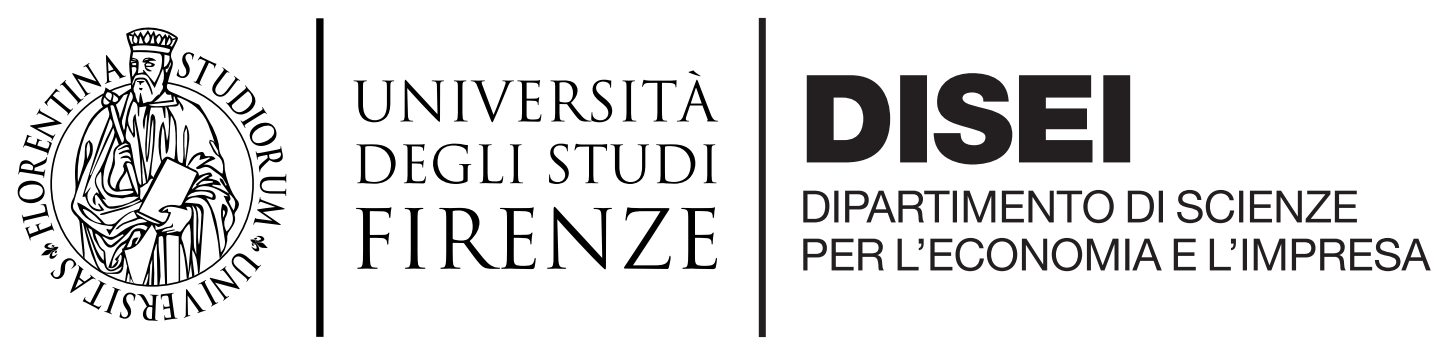

WORKING PAPERS - ECONOMICS

\title{
Mergers of Complements and Entry in Innovative Industries
}

\author{
FEDERICO ETRO
}

Working PAPER N. 15/2019 


\title{
Mergers of Complements and Entry in Innovative Industries
}

\author{
by Federico Etro ${ }^{1}$ \\ University of Florence
}

April 2019

\begin{abstract}
I study a merger between producers of complement inputs facing potential entry, with investment by the incumbents in deterministic cost reduction and by the entrants in probabilistic innovation, and then competition in prices. The merger solves Cournot complementarity problems in investment and pricing, which is what makes it profitable but also potentially anti-competitive. When the demand is inelastic the merger harms consumers by reducing $R \& D$ of the entrants if the incumbents are efficient enough (always when bundling is adopted). Instead, with a demand elastic enough, the merger increases consumer surplus (even with bundling).
\end{abstract}

Key words: Mergers, R\&D, Cournot complementarity, bundling, antitrust in high-tech industries.

JEL Code: L1, L4.

\footnotetext{
${ }^{1}$ I am grateful to Armin Schmutzler and two anonymous referees for important comments that improved the paper, and to Benno Buehler, Cristina Caffarra, Liliane Giardino-Karlinger, Alessandro Kadner-Graziano, Simon Loertscher, Pierre Regibeau, Robert Stillman and Tommaso Valletti for useful discussion, as well as to seminar participants at Cresse. However any responsibility is my own. I was involved in the Qualcomm-NXP case for third parties, but I am fully responsible for the views expressed here. Correspondence: Federico Etro, Florence School of Economics and Management, Via delle Pandette 32, D6-215, Firenze, Italia, 50127. Phone: 055-2759603. Email: federico.etro@unifi.it.
} 


\section{Introduction}

The literature of industrial organization has recently investigated the impact of mergers in case of endogenous innovation with a focus on antitrust implications (see Shapiro, 2012, and Gilbert and Greene, 2015). For instance, Motta and Tarantino (2017) and Federico et al. (2017) have examined horizontal mergers respectively in aggregative games of price competition between firms producing substitute goods and investing in cost reduction, and in symmetric contests with probabilistic innovation. ${ }^{2}$ In these and other related models a merger can exert a negative effect on consumer welfare driven by either higher prices or lower R\&D of the merged firms due to the internalization of business stealing effects. ${ }^{3}$ However, in other models, as those by Denicolò and Polo (2018), Bourreau and Jullien (2018) and Bourreau et al. (2018), horizontal mergers of firms producing substitute goods can spur innovation and benefit consumers by preventing duplication of efforts or expanding demand. ${ }^{4}$

I explore the alternative case of a merger between firms producing complement goods and investing in R\&D, a scenario that is traditionally associated with positive effects on consumer welfare driven by lower prices and strengthened by higher R\&D, due to the internalization of Cournot complementarities, except for cases where the merged entity adopts some form of mixed bundling to divert demand from rival producers with an ambiguous impact on consumer welfare (see Economides and Salop, 1992, and especially Choi, 2008). In contrast to this, my main result is that a merger of complements can harm consumers even in the absence of bundling and when it allows for the internalization of Cournot complementarities: the reason is that higher $\mathrm{R} \& \mathrm{D}$ by the merging incumbents reduces the incentives of the entrants to invest in $R \& D$ generating an increase in expected prices when downstream demand is sufficiently inelastic. Instead, when demand is elastic enough, the merger tends to benefit consumers even when bundling can be adopted and even if this deters entry, due to beneficial effects on cost reduction and pricing of the incumbents.

Conglomerate mergers between producers of complement goods have been the focus of a variety of antitrust cases, as those involving General Electric and Honeywell, Tetrapak and Laval Sidel, Intel and McAfee and few more cases in highly innovative industries. The critical aspects of these mergers concerned

\footnotetext{
${ }^{2}$ As well known, horizontal mergers with a fixed number of firms are hardly profitable with quantity competition (Salant et al., 1983), but are profitable under price competition (Deneckere and Davidson, 1985) and, more generally, in case of endogenous R\&D in cost reduction (Davidson and Ferrett, 2007).

${ }^{3}$ Schumpeterian theories featuring an inverse- $U$ relation between competition and innovation (Aghion and Griffith, 2005) suggest that mergers in highly concentrated sectors tend to reduce innovation, but their results are not general (Schmutzler, 2013). The negative impact of mergers on $R \& D$ can be overturned in the presence of gains from coordination of $R \& D$ investments with correlated outcomes, scale economies in R\&D and other synergies, an endogenous number of research projects for each firm (see Sah and Stiglitz, 1987) or endogenous entry of firms (on the neutrality of mergers in aggregative games with free entry see Davidson and Mukherjee, 2007, and Etro, 2007, Prop. 2.10).

${ }^{4}$ Bourreau et al. (2018) provide a more general analysis for the case of a merger to monopoly. See also Lopez and Vives (2016) on a general model of overlapping ownership.
} 
complement products that were separately produced by each of the merging firms (for instance jet engines by GE and a portfolio of avionics and nonavionics products by Honeywell $)^{5}$ and whose combination post-merger could foreclose entry. Bundling issues have been at the core of these cases for their anti-competitive implications. Recently, a proposed merger between Qualcomm and NXP has been cleared by the European antitrust authorities under conditions aimed at avoiding risks of foreclosure for actual and potential rivals. In this case, the merging firms produce complement components for smartphones, respectively baseband chipsets by Qualcomm and near-field communication (NFC) and secure element (SE) chips for contactless payments by NXP, which owns and licenses IP on the Mifare technology, an essential technology for high-end devices used as mobile wallets (for instance to pay for public transport or make other secure payments). The merger has been approved conditionally on ensuring interoperability of Qualcomm's basebands with NFC and SE products by competitors, excluding pure bundling of the two components, and continuing to license the Mifare technology to other producers for an eight-year period. ${ }^{6}$ These are appropriate remedies to avoid the negative effects of a conglomerate merger on the incentives of competitors to invest in product development and exert competitive pressure on the merged entity.

At a more general level, conglomerate mergers in high-tech industries often involve "must-have" inputs generating an inelastic demand for a composite good (for instance because there are not substitute producers of essential components protected by IP), while other mergers relate to composite goods with a more elastic demand (for instance because there are rivals producing imperfect substitutes for either the composite goods or their components). I formalize the idea that mergers can raise anti-competitive concerns in the former case and not in the latter.

\subsection{The main mechanism}

My main point can be presented with a simple example. Consider two suppliers of inputs $A$ and $B$ that are perfect complements in the production of a final good. They face a downward sloping demand $D(P)$ in the total price $P$ and produce at marginal $\operatorname{costs} c_{A}$ and $c_{B}$, which can be reduced through R\&D investment. The incumbents invest based on their (unilateral) incremental profit of a lower marginal cost, and underinvestment relative to the monopoly case occurs because the incumbents fail to internalize the effect of their investment on the profit of their rival. Therefore, a merger increases investments by the incumbents. Moreover (and abstracting from entry), such a merger is good for consumers for three reasons: first, it leads to direct price reductions because it fixes the traditional Cournot complementarity problem in pricing; second, it directly increases investment because it fixes the Cournot complementarity

\footnotetext{
${ }^{5}$ See Motta (2004, pp. 379-91).

${ }^{6}$ After this, the Qualcomm-NXP deal was stopped when China failed to grant regulatory approval.
} 
problem in $\mathrm{R} \& \mathrm{D}$, which reduces prices further; and third, by increasing production and profits it generates an additional incentive to invest in $R \& D$ and reduce costs and prices compared to the pre-merger situation.

Now, consider the role of a potential entrant. Suppose that, after a successful non-drastic innovation, an outsider can produce both inputs at zero cost for simplicity. Its $R \& D$ investment in the probability of entry is based on its expected profits. Upon entry, it must compete in prices with the incumbents and this price competition makes entry less profitable when the incumbent firms are more efficient. More precisely, the entrant has to set the limit price $C=c_{A}+c_{B}$, earning profits $\pi(C)=D(C) C$, which are increasing in $C .{ }^{7}$ In this scenario, the merger has two additional effects. By reducing the marginal costs, it reduces the limit price in case of entry, which is a fourth source of benefits for consumers. However, the reduction in the limit price reduces the incentives of the outsider to invest. Therefore this last effect is a source of harm to consumers, because the merger reduces the probability of entry compared to the pre-merger situation. If the demand function is elastic enough, the pricing benefits of the merger more than compensate the harm to consumers. But if the demand is quite inelastic the first three sources of consumer benefits evaporate and the fourth one can be more than compensated by the last effect, so that the merger harms consumers. Paradoxically, it is exactly the internalization of R\&D complementarities made possible by the merger that generates the negative effect on consumers by disincentivizing the investment of the entrant.

This example ignores the possibility of independent entry by separate producers of each input, which may increase the chances of entry and limit the anti-competitive effects of the merger. Therefore, I will develop a model with two entrants that can produce new cheaper (or superior) versions of each input and consider a two-stage game: in the first stage the incumbents invest in cost reduction and each entrant in probabilistic $R \& D$ and in the second stage price competition takes place. I start by considering the case of a fixed willingness to pay for the final good to show that consumer harm can indeed materialize. ${ }^{8}$ This is a benchmark where the merger would be completely neutral in the absence of Cournot effects on R\&D of the merging firms. ${ }^{9}$ In such a case the merger always reduces the incentives of the entrants to invest in $R \& D$ and the expected price for the consumers increases post-merger as long as the incumbents are already efficient enough in the pre-merger situation. While I use a consumer welfare standard in the analysis, I show that the merger can also reduce total welfare.

\footnotetext{
${ }^{7}$ Indeed $\pi^{\prime}(C)=D(C)+C D^{\prime}(C)$ with $\pi^{\prime}(0)=D(0)>0$ and $\pi^{\prime}(\bar{P})=0$ at the monopolistic price of the entrant $\bar{P}$, which is assumed above $C$ to have non-drastic innovations.

${ }^{8}$ As noticed by a referee, in case of a fixed willingness to pay the merger accomplishes the same $\mathrm{R} \& \mathrm{D}$ coordination as a research joint venture. This is not the case under a downward sloping demand when the merger allows the incumbents to coordinate also on price changes (though, in principle, a patent pool could accomplish price coordination as well). Accordingly, some of the antitrust implications of the model can be applied also to research joint ventures.

${ }^{9}$ For a critical assessment of Cournot effects on R\&D for complement goods see Llobet and Padilla (2017). They argue that in the presence of threats of patent litigation the royaltystacking problem can be eliminated: in such a case the benefits from a merger of licensors of complement technologies are diminuished further. I abstract from this effect.
} 
Finally, I extend the analysis to a downward sloping demand.

\subsection{Literature review}

Few recent studies have emphasized the possibility that mergers between firms producing complement goods can generate anti-competitive concerns, including Denicolò (2000), Alvisi et al. (2011), Masson et al. (2014) and Chen and Rey (2015), but none of them focuses directly on the innovation channel, which is crucial here.

My work is also strictly related to recent theories of merger analysis with endogenous innovation: these include Davidson and Ferrett (2007), Matsushima et al. (2013), Lopez and Vives (2016), Salinger (2016), Motta and Tarantino (2017), Federico et al. (2017, 2018), Bourreau and Jullien (2018), Bourreau et al. (2018) and Marshall and Parra (2018). An excellent review of this emerging literature is in Jullien and Lefouili (2018), who distinguish different effects of horizontal mergers on innovation, including a negative "margin expansion" effect, a positive "demand expansion" effect, an ambiguous "innovation diversion" effect and a positive "spillover" effect. The first one prevails in Motta and Tarantino (2017) and Federico et al. (2018), the second in Bourreau and Jullien (2018), the third is present in Bourreau et al. (2018), and the last is the main source of merger efficiencies in the model of Lopez and Vives (2016) on overlapping ownership. All of these studies focus on horizontal mergers between producers of substitutes, while my work is focused on mergers between complements. In particular, I focus on the effects on pricing, cost reduction by the merging firms and probabilistic R\&D by the entrants, while I abstract from the positive effects of mergers due to demand expansion and internalization of R\&D spillovers, which are already well understood. ${ }^{10}$

Part of the work is closely related to theories of anti-competitive tying, some of which have analyzed whether a merger with bundling of complementary goods can soften or tighten competition (see Matutes and Regibeau, 1992, for a classic analysis in a different framework). ${ }^{11}$ Choi and Stefanadis (2001) have studied the role of a commitment to pure bundling by an incumbent producing two complement goods to deter entry of rivals that invest in alternative components. Their work, unlike the present one, does not consider a merger between two incumbents with potentially different marginal costs that can be reduced with deterministic R\&D activity, and is limited to the case of a fixed willingness to pay (with a multiplicity of price equilibria that, as I will show, can be avoided under a more general analysis). Instead, Choi (2008) focuses on product differentiation between four composite goods and mixed bundling by the merged firm, with high prices for the stand-alone components and low price for

\footnotetext{
${ }^{10}$ I focus on competition in posted prices between firms. Etro (2018) analyzes the case of Nash barganining and discusses further extensions.

${ }^{11}$ See Fumagalli et al. (2018) for an excellent survey. For more recent analysis of anticompetitive bundling of perfect complements see Choi and Jeon (2016), Etro and Caffarra (2017) and Hurkens et al. (2018), though these works abstract from a merger.
} 
the bundle. ${ }^{12}$ Choi's extension to deterministic R\&D activity by all the four firms adds ambiguous implications on welfare impact of the merger. My work can be seen as complementary to those of Choi and Stefanadis (2001) and Choi (2008).

The rest of the article is organized as follows. Section 2 presents the baseline model with a perfectly rigid demand. Section 3 discusses the case of a downward sloping demand curve. Section 4 concludes. Proofs are in the Appendix.

\section{A simple model of anti-competitive mergers}

The baseline model is as simple as possible. A final good includes two components $A$ and $B$ that are perfect complements. Consumers have a fixed willingness to pay for the composite good which is normalized to one: this is the typical case of firms producing components that are considered as "must have" in the market (for instance because they are protected by IPRs that are essential to produce a composite good with an inelastic demand). The two incumbent firms produce the components at marginal costs respectively $c_{A}$ and $c_{B}$ which can be reduced through investment. Two entrants can innovate and produce substitute components at a lower marginal costs if they are successful (for instance by patenting a new technology alternative to one by an incumbent). Notice that the model can be easily reinterpreted in terms of innovation in quality improvements rather than cost reductions.

The game has two stages. In the first stage, all firms invest simultaneously in R\&D. Once the outcome of innovation is realized, firms compete in posted prices in the second stage. ${ }^{13}$ The game is solved by backward induction.

The investment of the incumbents is deterministic and aimed at reducing their marginal cost of production: in particular, each incumbent has a maximum cost $\bar{c} \in(0,1 / 2)$ if it does not invest, but can spend $I(\bar{c}-c)$ to reduce the marginal cost to $c<\bar{c}$, with $I^{\prime}(\cdot)>0, I^{\prime \prime}(\cdot)>0, I(0) \geq 0$ and $I^{\prime}(0)=0 .{ }^{14} \mathrm{R} \& \mathrm{D}$ on cost reduction in complementary products creates a Cournot externality: if there was no entry threat, the only effect of the merger of the incumbents would be to internalize the impact of their investment on the joint profits.

\footnotetext{
${ }^{12}$ While I abstract from product differentiation and mixed bundling, the linear-demand model of Choi (2008) implies that the merger benefits consumers when the demand of a bundle is very sensitive to its own price and very rigid in the prices of the rivals (so that gains from Cournot effects are large), and the merger harms consumers when the demand is rigid in its own price but highly elastic in the price of others (so that bundling diverts demand from the rivals), a case that can also lead to the adoption of pure bundling.

${ }^{13}$ In the interpretation of the model in terms of quality innovations, the incumbents invest to increase the willingness to pay for their components, and the entrants invest to create new components for which users have a higher willingness to pay relative to the components of the incumbents. In particular $1-c_{A}-c_{B}$ should be re-interpreted as the willingness to pay for the composite good provided by the incumbents and $c_{i}$ as the increase in the willingness to pay when the new component of entrant $i$ is used.

${ }^{14} \mathrm{I}$ allow for a positive fixed cost, therefore the optimal investment of the incumbents can indeed be zero (by leaving their marginal cost at $\bar{c}$ ), but most of the analysis will focus on positive investments.
} 
The investment of the entrants is probabilistic and aimed at inventing a new component produced at a lower cost normalized to zero. ${ }^{15}$ In particular, each entrant for component $i=A, B$ innovates with probability $z_{i} \in[0,1]$ at the cost $F\left(z_{i}\right)=\frac{1}{2} z_{i}^{2}$, where the quadratic specification is assumed for convenience (I will later consider a more general technology).

Before analyzing the game, it is useful to establish the first best outcome for this market. Welfare can be expressed as the net surplus generated by the goods, and the social planner problem is its maximization:

$$
\max _{c_{A}, c_{B}, z_{A}, z_{B}} 1-\sum_{j=A, B}\left[c_{j}\left(1-z_{j}\right)+F\left(z_{j}\right)+I\left(\bar{c}-c_{j}\right)\right]
$$

where the first term in the summation is the expected production cost of a component, the second term is the R\&D cost for an entrant and the third one is the $R \& D$ investment in cost reduction for an incumbent. When there is an interior solution, it equates the marginal revenues and costs of the investment of each incumbent according to $1-z_{j}=I^{\prime}\left(\bar{c}-c_{j}\right)$ and of each entrant according to $c_{j}=F^{\prime}\left(z_{j}\right)$. The quadratic specification for the cost of the entrants provides a symmetric solution where $c_{A}=c_{B}=z_{A}=z_{B}=c^{F B}$ satisfies the optimality condition: ${ }^{16}$

$$
1-c^{F B}=I^{\prime}\left(\bar{c}-c^{F B}\right)
$$

which equates the marginal social benefit of cost reduction to its marginal cost. Ordinarily, the market cannot reach efficiency because firms bearing the costs of innovation do not appropriate the entire surplus of it.

\subsection{Pre-merger situation}

In this section I study the pre-merger situation starting from the pricing stage. The incentives to invest depend on the expected profits in this stage as in Choi and Stefanadis (2001).

If there is no successful innovation by either entrant, the incumbents set prices to share the surplus $1-c_{A}-c_{B}$ : as standard, there is indeed a continuum of equilibria where each incumbent gets a different fraction of the surplus, but I will focus on the symmetric equilibrium in which each incumbent obtains half of it; consumers have no surplus in this case. If both entrants innovate, they outbid the incumbents selling at prices just below their marginal costs, obtaining respectively $c_{A}$ and $c_{B}$; this leaves surplus $1-c_{A}-c_{B}$ to consumers.

\footnotetext{
${ }^{15}$ It is natural to think that the entrants invest in new products under uncertainty and the incumbents can improve their existing technology with lower or no uncertainty. Two remarks are in order. First, for the incumbents one can think of either process innovation (cost reduction) or product innovation (demand-enhancing innovations), or even both of them as often is the case (Athey and Schmutzler, 1995). Second, the main results are robust to the alternative assumption of probabilistic R\&D also by the incumbents (at the cost of complicating the analysis). The crucial assumption here is that entry by the outsiders is in probabilistic R\&D.

${ }^{16}$ I will occasionally use the additional assumption that the cost of the incumbents is $I(\bar{c}-$ $c)=\beta(1 / 2-c)^{2}$, where $\beta>0$ parameterizes the difficulty of deterministic innovation. This provides $c^{F B}=\max \left(\frac{\beta-1}{2 \beta-1}, 0\right)$.
} 
Finally, if only one entrant innovates, say in component $i=A, B$, there is again a continuum of Bertrand equilibria, where the successful entrant obtains a fraction of the surplus created by its innovation, and the remaining incumbent obtains the rest of the total surplus: I index these multiple equilibria by $\lambda \in(0,1]$ as the fraction of the rents created by the innovation that is appropriated by the entrant: the successful entrant and the monopolistic incumbent share the surplus $c_{i}$, with rents $\lambda c_{i}$ for the former and $1-\lambda c_{i}-c_{j}$ for the latter (including the rent from its own component); consumers retain zero surplus also in this case.

The expected consumer surplus is:

$$
\mathbb{E}(C S)=z_{A} z_{B}\left(1-c_{A}-c_{B}\right)
$$

which corresponds to the probability of a joint innovation multiplied by the surplus of consumers in that state of the world. Moreover, I can express the expected profits of the incumbents producing component $i, j=A, B$ as:

$$
\mathbb{E}\left(\pi_{i}\right)=\left(1-z_{i}\right)\left(1-z_{j}\right) \frac{1-c_{i}-c_{j}}{2}+\left(1-z_{i}\right) z_{j}\left(1-\lambda c_{j}-c_{i}\right)-I\left(\bar{c}-c_{i}\right)
$$

and the expected profits of the entrants in component $i, j=A, B$ as:

$$
\mathbb{E}\left(\pi_{i}^{e}\right)=z_{i} z_{j} c_{i}+z_{i}\left(1-z_{j}\right) \lambda c_{i}-F\left(z_{i}\right)
$$

I now consider the first stage where the four firms decide simultaneously on their R\&D investments. The FOCs of the incumbents to maximize (3) are:

$$
\frac{\left(1-z_{i}\right)\left(1-z_{j}\right)}{2}+\left(1-z_{i}\right) z_{j}=I^{\prime}\left(\bar{c}-c_{i}\right) \text { for } i, j=A, B
$$

where the marginal benefit of investment by $i$ is decreased by the probability of innovation of the direct rival $z_{i}$, but it is increased by the probability of innovation of the non-competing entrant $z_{j}$, since each incumbent makes more profits when there is an innovation by the non-competing entrant. The FOCs of the entrants to maximize (4) deliver the following best response functions for the probability of innovation of each entrant:

$$
z_{i}=z_{j} c_{i}+\left(1-z_{j}\right) \lambda c_{i} \text { for } i, j=A, B
$$

which shows strategic complementarity with the other entrant and strategic substitutability with the competing incumbent. Under symmetry, the unique equilibrium investment of each entrant is:

$$
z(\lambda, c)=\frac{\lambda c}{1-c(1-\lambda)} \in[0, c]
$$

which is increasing in $\lambda$ and in $c$, since entrants find it more profitable to invest when they can appropriate more rents and when they can set higher prices due to the inefficiency of the incumbents. Under symmetry, the investment of the 
incumbents satisfies $\frac{1-z^{2}}{2}=I^{\prime}(\bar{c}-c)$. The marginal benefit of investment on the left hand side is decreasing overall in the investment of the entrants. Replacing $z=z(\lambda, c)$ I obtain an implicit expression for the investment of the incumbents:

$$
\frac{\left(1-c^{*}\right)\left[1-c^{*}(1-2 \lambda)\right]}{2\left[1-c^{*}(1-\lambda)\right]^{2}}=I^{\prime}\left(\bar{c}-c^{*}\right)
$$

associated with the equilibrium probability of innovation $z\left(\lambda, c^{*}\right)$. The marginal benefit of investment for the incumbents ranges between $1 / 2$ under full price squeeze $(\lambda=0)$ and $\left(1-c^{* 2}\right) / 2$ when the entrant can extract the entire surplus of its innovation $(\lambda=1)$ : in the former case the entrants do not invest $(z=0)$, and when they can extract the entire surplus they invest the maximum amount $(z=c)$. In either case, it is easy to verify that the equilibrium entails too little investment by the two incumbents compared to the first best in (1), while the investment of the entrants is too much when $\lambda$ is large (high appropriability) and too little when $\lambda$ is small. ${ }^{17}$

Since each incumbent neglects the positive impact of its investment on the profits of the other incumbent, there is underinvestment also from the point of view of the two firms. This underinvestment in cost reduction implies that, in case of entry, the innovators can set high prices, which is of course detrimental to consumers. This corresponds to a Cournot complementarity problem, where both incumbents and consumers could benefit from further investment in cost reduction. The joint profits of the incumbents can be computed as:

$$
\mathbb{E}\left(\pi_{J}(c)\right)=\left(1-z(\lambda, c)^{2}\right)(1-2 c)+2(1-z(\lambda, c)) z(\lambda, c) c(1-\lambda)-2 I(\bar{c}-c)
$$

to be evaluated in the equilibrium cost $c^{*}$. This is a continuous and nonmonotonic function maximized for an intermediate value of $\lambda$ that optimizes the trade-off between appropriating the expected surplus created by the innovations of the entrants and incentivizing the same innovations (for instance, when $c^{*}=\bar{c}$, the joint profits are maximized by $\lambda=1 / 3$ ).

The consumer surplus in equilibrium is given by the following function:

$$
\mathbb{E}(C S(c))=\frac{(\lambda c)^{2}(1-2 c)}{[1-c(1-\lambda)]^{2}}
$$

to be evaluated at the equilibrium $\operatorname{cost} c^{*}$. Notice that $\mathbb{E}(C S(c))$ is an inverse- $\mathrm{U}$ shaped function of $c$, with zero value for $c=0$ and $c=1 / 2$ and maximum consumer surplus obtained when the marginal cost is given by $\hat{c}(\lambda)=\frac{3-\sqrt{9-4(1-\lambda)}}{2(1-\lambda)}$ with $\hat{c}(1)=1 / 3$ and $\hat{c}(0) \rightarrow 0.38$. Only by accident the equilibrium marginal cost of the incumbents $c^{*}$ would match such a "golden rule". When it is above this level, both the incumbents and the consumers would gain from an additional investment in cost reduction, because this would increase the expected

\footnotetext{
${ }^{17}$ As I will show in Section 3, there are good reason to consider the case of full appropriability as the relevant one when the demand is approximately inelastic. In the example with quadratic investment cost, for $\lambda=1$ one obtains $c^{*}=\max \left(2 \beta-\sqrt{4 \beta^{2}-2 \beta+1}, 0\right)$.
} 
profits of the incumbents and reduce the price in case of entry as well as the expected price. Instead, when the equilibrium marginal cost is below this cutoff, an additional investment would benefit the incumbents, but would harm consumers through a reduction in the probability of entry, which increases the expected price.

\subsection{Post-merger situation}

Let us now consider the merger between the two incumbents. While price competition takes place as before, the investment in each component for the merged firm is now selected to maximize the joint profits:

$$
\begin{aligned}
\mathbb{E}\left(\pi_{M}\right)= & \left(1-z_{A}\right)\left(1-z_{B}\right)\left(1-c_{A}-c_{B}\right)+\left(1-z_{A}\right) z_{B}\left(1-\lambda c_{B}-c_{A}\right) \\
& +\left(1-z_{B}\right) z_{A}\left(1-\lambda c_{A}-c_{B}\right)-I\left(\bar{c}-c_{A}\right)-I\left(\bar{c}-c_{B}\right)
\end{aligned}
$$

The merger fixes the Cournot complementarity problem, increasing the investment of the incumbents. The investment rules of the entrants, instead are the same as before. As I show in the Appendix, this delivers an equilibrium investment by the entrants $z^{M}=z\left(\lambda, c^{M}\right)$ where the marginal cost of the incumbents $c^{M}$ satisfies:

$$
\frac{\left(1-c^{M}\right)\left[1-c^{M}\left(1-\lambda-\lambda^{2}\right)\right]}{\left[1-c^{M}(1-\lambda)\right]^{2}}=I^{\prime}\left(\bar{c}-c^{M}\right)
$$

It is easy to verify that the merger induces the incumbents to always increase their investment by internalizing the Cournot complementarity (indeed, the marginal benefit of investment for the incumbents ranges between 1 under full price squeeze and $1-\left(c^{M}\right)^{2}$ when the entrant can extract the entire surplus of its innovation), which in turn forces the entrants to reduce their investment. Compared to the first best, now the merged incumbents invest too much and the entrants invest always too little. ${ }^{18}$

The expected profits for the merged firms are $\mathbb{E}\left(\pi_{M}\right)=\mathbb{E}\left(\pi_{J}\left(c^{M}\right)\right)$, where the function $\mathbb{E}\left(\pi_{J}(c)\right)$ is defined by (8), and they must increase compared to the pre-merger situation because the merger delivers coordination of R\&D. Expected consumer surplus is still given by the function $\mathbb{E}(C S(c))$ in $(9)$ to be evaluated in $c^{M}$. Remembering that $\mathbb{E}(C S(c))$ is an inverse-U shaped function, I can prove (in the Appendix) that the merger reduces consumer surplus $\mathbb{E}\left(C S\left(c^{M}\right)\right)$ whenever the incumbents are efficient enough before the merger:

Proposition 1. The merger is profitable, reduces the investment of the entrants and increases the investment of the merging parties, with a reduction of consumer surplus if the merging firms are efficient enough in the pre-merger situation.

It should be clear that endogenous R\&D has a key role to generate an impact on consumers. The merger would be neutral if the incumbents could not

\footnotetext{
${ }^{18}$ Assuming the quadratic investment cost as before with $\lambda=1$, I have $c^{M}=\max (\beta-$ $\left.\sqrt{\beta^{2}-\beta+1}, 0\right)$, which is always below the pre-merger value.
} 
invest to reduce their costs below $\bar{c}$. It would be also neutral if there were no Cournot complementarities in cost reductions, because the investment of the incumbents would not change post-merger. It is the opportunity to internalize the Cournot complementarities after the merger (or equivalently after the formation of a research joint venture) that opens up the space for consumer harm: while in principle this could exert beneficial effects on consumers through price reductions, it also reduces the incentives to invest of the entrants with negative effects that can more than compensate the price effects.

I have focused the analysis on consumer surplus, which is the relevant standard for most antitrust authorities. However, one may want to verify if the results are robust under a total welfare standard. In this environment one can compute total expected welfare as the sum of consumer surplus and expected profits of the four firms as a function of the marginal cost: ${ }^{19}$

$$
\mathbb{E}(W(c))=\frac{(1-c)^{2}[1-2 c(1-\lambda)]}{[1-c(1-\lambda)]^{2}}-2 I(\bar{c}-c)
$$

This welfare function also has an inverse- $\mathrm{U}$ shaped function of $c$ : an increase of $c$ reduces the sum of expected consumers surplus and industry profits net of the costs of deterministic R\&D (the first term) but reduces the total costs in deterministic $\mathrm{R} \& \mathrm{D}$ (the second term). The implication is that the merger also delivers a reduction of total welfare if the merging firms are efficient enough in the pre-merger situation. However, the impact depends on the R\&D technology of the incumbents, which was irrelevant for consumer surplus, therefore a reduction in the latter may be associated with either a reduction or an increase of total welfare. ${ }^{20}$

\subsection{Merger with bundling}

Until now, the only purpose of the merger was to coordinate the R\&D activity, therefore the incumbents could have reached the same result with a research joint venture. I now introduce a new purpose of the merger, which is related to the pricing stage. Let us consider the possibility of a commitment to pure bundling, in the sense that the merged firm offers the bundle at a single price and commits not to sell any of its components as standalone products even if one of the entrants innovates. ${ }^{21}$

Unless both entrants innovate, the merged entity sets a unitary price for the bundle and obtains $1-c_{A}-c_{B}$, while consumers have no surplus. Only when

\footnotetext{
${ }^{19}$ In particular, total welfare is $\mathbb{E}\left(W\left(c^{*}\right)\right)$ pre-merger and $\mathbb{E}\left(W\left(c^{M}\right)\right)$ post-merger.

${ }^{20}$ For instance, assuming $\lambda=1$ and the quadratic cost function, total welfare $\mathbb{E}(W(c))=$ $(1-c)^{2}-\beta\left(\frac{1}{2}-c\right)^{2}$ is maximized at the first best level $c^{F B}$, which can be above or below the one maximizing consumer surplus.

${ }^{21}$ The introduction of an elastic demand will deliver also a change in the total price of the bundle by the merged entity (due to the Cournot effect), but this additional effect is absent here. Notice that a patent pool between separate incumbents could also coordinate the price of the bundle, but after entry each incumbent would have an incentive to leave the patent pool, so that the commitment to bundling would not be credible.
} 
both the entrants innovate, they can outbid the incumbents obtaining $c_{A}$ and $c_{B}$, which leaves consumer surplus $1-c_{A}-c_{B}$. The expected profits of the merged entity are:

$$
\mathbb{E}\left(\pi_{M}^{B}\right)=\left(1-z_{A} z_{B}\right)\left(1-c_{A}-c_{B}\right)-I\left(\bar{c}-c_{A}\right)-I\left(\bar{c}-c_{B}\right)
$$

and the expected profits of the entrant producing component $i, j=A, B$ are:

$$
\pi_{i}^{e}=z_{i} z_{j} c_{i}-\frac{z_{i}^{2}}{2}
$$

The only Nash equilibrium of the innovation game implies zero investment by the entrants with an investment by the incumbents that satisfies:

$$
1=I^{\prime}\left(\bar{c}-c^{B}\right)
$$

Bundling reduces the incentives to invest of the entrants as in Choi and Stefanadis (2001), and the impact is magnified by the fact that each firm does not internalize the beneficial impact of its investment on the other. ${ }^{22}$ Here, this increases further the investment of the incumbents because of a scale effect: the certain rent has a larger expected size compared to the merger without bundling, and this incentivizes further investment of the merging firms. However, none of the benefits of this additional investment reaches consumers since the incumbents appropriate all of it. In the Appendix I prove the following result on the impact of a merger between producers of complements:

Proposition 2. When a commitment to pure bundling is feasible:

a) the merged entity adopts pure bundling when a single innovator appropriates a large enough fraction of the value of its innovation, and in such a case the merger reduces further the investment of the entrants and increases further the investment of the merging firms, always with a reduction in consumer surplus;

b) otherwise the merger occurs without bundling and delivers a reduction of consumer surplus if the merging firms are efficient enough in the pre-merger situation.

Last, I note that total welfare after a merger with bundling is just given by the profits of the merged firm. It is then easy to verify that the adoption of bundling is compatible with an increase in welfare even if it always harms consumers.

\subsection{Extensions}

The result on full entry deterrence under bundling depends on the assumptions made on the cost of probabilistic innovation. However, in the Appendix I generalize the model with a general cost function and show that the spirit of the results remains unchanged:

\footnotetext{
${ }^{22}$ With a quadratic investment cost one obtains $c^{B}=\left(\frac{1}{2}-\frac{1}{2 \beta}, 0\right)$.
} 
Proposition 3. Under a general function for the cost of probabilistic innovation increasing and convex, the merger is profitable, reduces the investment of the entrants and increases the investment of the merging parties, but pure bundling does not necessarily deter entry.

The main results are also robust to other extensions formalized in Etro (2018). One can consider a counter-merger between the two entrants: this reduces the investment of the incumbents and increases the one of the entrants, which makes the entrants better off and increases also consumer surplus. The implication is that the profit gains from the merger are reduced or even eliminated, but when the merger takes place it remains detrimental to consumers when the incumbents are efficient enough. Moreover, when the merger with pure bundling is profitable in the absence of a counter-merger, it remains profitable and harmful to consumers. Finally, the possibility of a counter-merger enlarges the set of parameters for which a commitment to bundling is optimal, and therefore it makes consumer harm more likely.

One can consider precommitments to R\&D by the same incumbents, as often realistic for firms with the leading technology (Czarnitzki et al., 2014): also in this case the merger reduces further the investment of the entrants and increases further the investment of the merging parties due to a first mover strategic effect. A novel result for this case is that efficient incumbents reduce their investment when they can adopt bundling. In practice bundling and investment in cost reductions are substitute tools in reducing the probability of entry: once a commitment to bundling can be credibly adopted, the merged entity can reduce its investment in $R \& D$ without increasing the likelihood of entry by the rivals.

\section{Downward sloping demand}

In this section I generalize the baseline model to take into account a downward sloping demand for the composite good. In such a case the merged entity always has an incentive to reduce prices with additional indirect effects on R\&D: such new pro-competitive effects can more than compensate the anti-competitive effects emphasized until now, but of course it is the shape of the demand function that determines whether this is the case.

To microfound an elastic demand function I assume that final consumers have a quasilinear indirect utility $V=v(P)+E$, where $E$ is income and $v(P)$ is decreasing and convex in the total price $P=p_{A}+p_{B}$, where $p_{i}$ is the price of component $i=A, B$, with $v(1)=0$ to preserve the unitary choke price. The demand function is $D(P)=\left|v^{\prime}(P)\right|$ by Roy's identity. It is particularly useful to adopt an isoelastic specification $v(P)=\frac{(1-P)^{\gamma+1}}{\gamma+1}$ with $\gamma \geq 0$, that provides the demand function: ${ }^{23}$

$$
D(P)=(1-P)^{\gamma}
$$

\footnotetext{
${ }^{23}$ Extensions to multiple goods exploiting indirect additivity are gaining rapid adoption in the analysis of monopolistic and imperfect competition (see Bertoletti and Etro, 2016, 2017, and Nocke and Schutz, 2018).
} 
This nests the case of a fixed willingness to pay of Section 2 when $\gamma \rightarrow 0$ and the familiar case of a linear demand when $\gamma=1,{ }^{24}$ as well as other cases where $\gamma \in(0, \infty)$ parameterizes the demand elasticity $\left|\frac{d \ln D}{d \ln P}\right|=\frac{\gamma P}{1-P}$. I also assume that the innovation of the entrants is not drastic. ${ }^{25}$

Let me revisit the analysis of price competition depending on which goods are developed. If there is no successful innovation by either entrant the profits of the incumbents are $\pi_{i}=\left(1-p_{A}-p_{B}\right)^{\gamma}\left(p_{i}-c_{i}\right)$. In case of independent incumbents, this implies a Bertrand equilibrium with profits:

$$
\pi_{i}=\gamma^{\gamma}\left(\frac{1-c_{A}-c_{B}}{2+\gamma}\right)^{\gamma+1}
$$

In case of a merged entity, the two prices are chosen to maximize joint profits, which delivers a price below the earlier total price since the merger fixes the Cournot complementarity in pricing. In such a case the joint profits increase to:

$$
\pi_{M}=\gamma^{\gamma}\left(\frac{1-c_{A}-c_{B}}{1+\gamma}\right)^{\gamma+1}
$$

If both entrants innovate, they outbid the incumbents selling at $p_{i}=c_{i}$ for $i=A, B$, and obtain the following profits:

$$
\pi_{i}^{e}=\left(1-c_{A}-c_{B}\right)^{\gamma} c_{i}
$$

Finally, if only one entrant innovates, say in component $i=A, B$, it adopts limit pricing $p_{i}=c_{i}$ leaving the other incumbent $j=B, A$ to maximize its profits $\pi_{j}=\left(1-p_{j}-c_{i}\right)^{\gamma}\left(p_{j}-c_{j}\right)$. This avoids the multiplicity of sub-game equilibria of the Choi and Stefanadis (2001) model and delivers profits for the entrant and the incumbent given respectively by:

$$
\pi_{i}^{e o}=\gamma^{\gamma}\left(\frac{1-c_{A}-c_{B}}{1+\gamma}\right)^{\gamma} c_{i} \text { and } \pi_{j}^{o}=\gamma^{\gamma}\left(\frac{1-c_{A}-c_{B}}{1+\gamma}\right)^{\gamma+1}
$$

where the latter is the same as $\pi_{M}$. Notice that (for $\gamma$ low enough) entry is less profitable when the rival incumbent is more efficient, which is what drives the anti-competitive effect of the merger also in this context.

In the innovation stage before the merger the expected profits of the incumbents producing component $i, j=A, B$ are:

$$
\mathbb{E}\left(\pi_{i}\right)=\left(1-z_{i}\right)\left(1-z_{j}\right) \pi_{i}+\left(1-z_{i}\right) z_{j} \pi_{M}-I\left(\bar{c}-c_{i}\right)
$$

\footnotetext{
${ }^{24}$ See Amir et al. (2016) for a related discussion on pricing and consumer surplus in linear demand models.

${ }^{25}$ The ansatz for this, which holds in equilibrium, is $c<1 /(\gamma+3)$, requiring a low marginal cost in equilibrium or a demand that is not too convex. It is not difficult to extend the analysis to the case where the innovation is drastic with similar results. I should remark that in such a case a counter-merger by the entrants could induce further gains for consumers by fixing also the Cournot complementarity problem in pricing of the entrants.
} 
and the expected profits of the entrants in component $i, j=A, B$ are:

$$
\mathbb{E}\left(\pi_{i}^{e}\right)=z_{i} z_{j} \pi_{i}^{e}+z_{i}\left(1-z_{j}\right) \pi_{i}^{e o}-\frac{z_{i}^{2}}{2}
$$

After the merger the expected profits of the entrants are the same, but the expects profits of the merged entity become:

$$
\mathbb{E}\left(\pi_{M}\right)=\left(1-z_{i} z_{j}\right) \pi_{M}-I\left(\bar{c}-c_{j}\right)-I\left(\bar{c}-c_{i}\right)
$$

On this basis, one can compute the Nash equilibrium of the innovation game and determine the impact of the merger. To build the intuition of the results, I start from two particular cases, corresponding to a perfectly rigid demand and a linear demand.

The case where $\gamma \rightarrow 0$ delivers the limit of a perfectly rigid demand with a unitary willingness to buy, as in the baseline model of the last section. The key difference is that equilibrium multiplicity disappears in this limit of Bertrand competition, and the equilibrium profits approach those where the entrants can extract the full surplus of their innovations in the baseline model (namely with $\lambda=1$ ). Accordingly, it is useful to amend the results of the baseline model with a much stronger result: in the limit case of an almost perfectly rigid demand, the merger is profitable, reduces the investment of the entrants and increases the investment of the merging parties, with a reduction of consumer surplus if the merging firms are efficient enough. When a commitment to pure bundling is feasible, the merged entity adopts it always, and consumer surplus decreases. ${ }^{26}$

The case where $\gamma=1$ delivers a linear demand, and one can fully characterize the equilibria and draw unambiguous conclusions on the impact of the merger. In this case there is a new and positive impact due to the internalization of pricing externalities between the merging firms. This does not affect directly the profitability of entry. However, there is also a positive impact of the merger on the investment of the incumbents due to the internalization of $\mathrm{R} \& \mathrm{D}$ externalities, and this is always intensifying post-entry competition and reducing the probability of entry. The novelty is that under a linear demand the net impact on consumer surplus is always positive, and this holds also in case of bundling. In particular, in the Appendix I prove the following result:

Proposition 4. Under a linear demand for the composite good, the merger is profitable, increases the investment of the incumbents, reduces the investment of the entrants and increases consumer surplus. When a commitment to pure bundling is feasible, the merged entity always adopts it, and consumer surplus increases.

The linear case is characterized by a demand function elastic enough to ensure positive gains from the merger. I can now move to the general case. In

\footnotetext{
${ }^{26} \mathrm{~A}$ by-product of this allows me to revisit and strengthen the results of the Choi and Stefanadis (2001) model: bundling by a producer of complements subject to innovative entry is always profitable in front of an almost perfectly rigid demand, and it deters entry.
} 
the Appendix I show that the parameter $\gamma$ is crucial to determine the impact of the merger. Reducing $\gamma$ toward zero makes it more likely that the merger becomes anti-competitive because a lower portion of the gains created by the merger and by the entrants is translated to consumers and a higher portion is appropriated by the incumbents. Instead, increasing $\gamma$ makes it more likely that the merger increases consumer surplus by reducing expected prices due to both the Cournot complementarity effect and the innovation effect:

Proposition 5. Under an elastic demand for the composite good $D(P)=$ $(1-P)^{\gamma}$ with $\gamma>0$ and quadratic functions for the RED technology, when a commitment to pure bundling is feasible, the merged entity always adopts it, and consumer surplus decreases if and only if $\gamma<\hat{\gamma}$ for a positive cut-off $\hat{\gamma}$.

As in the baseline model, similar results can be obtained for the impact on total welfare. And as I argued in the Introduction, the spirit of the results holds under more general demand functions: the merger induces the incumbents to reduce prices and increase investment, which forces the entrants to reduce prices as well, but also to reduce their R\&D investment.

\section{Conclusion}

The model presented here applies to the frequent cases of mergers between firms producing complement products in industries where $\mathrm{R} \& \mathrm{D}$ is important. When the demand for the composite good is rigid, for instance because it is a "must have" component between multiple components for the production of a final good, a merger of complements can raise anti-competitive concerns because the direct positive effects for consumers from the strategies of the merging firms (lower prices and higher $\mathrm{R} \& \mathrm{D}$ ) are more than compensated by the indirect negative effects from the R\&D investment of the non-merging firms. Such an outcome is overturned when the demand for the composite good is elastic enough (for instance due to substitutability with alternative components): in such a case the merger increases consumer surplus because a big enough portion of the benefits of innovation is translated into lower prices, and this happens also when the merging firms adopt pure bundling strategies to limit entry.

The analysis could be extended in other directions, including endogenous size of the innovations of the entrants, research spillovers, imperfect complementarity between different components or imperfect substitutability between rival components and endogenous entry in the contest for product innovation. 


\section{References}

Aghion, Philippe and Rachel Griffith, 2005, Competition and Growth: Reconciling Theory and Evidence, Cambridge: MIT Press

Alvisi, Matteo, Emanuela Carbonara, and Francesco Parisi, 2011, Separating Complements: the effects of competition and quality leadership, Journal of Economics, 103, 2, 107-131

Amir, Rabah, Jim Y. Jin, Gerald Pech and Micheal Tröge, 2016, Prices and Deadweight Loss in Multiproduct Monopoly, Journal of Public Economic Theory, 18, 3, 346-362.

Athey, Susan and Armin Schmutzler, 1995, Product and Process Flexibility in an Innovative Environment, The RAND Journal of Economics, 26, 4, 557-74

Bertoletti, Paolo and Federico Etro, 2016, Preferences, Entry and Market Structure, The RAND Journal of Economics, 47, 4, 792-821

Bertoletti, Paolo and Federico Etro, 2017, Monopolistic Competition when Income Matters, The Economic Journal, 127, 603, 1217-43

Bourreau, Marc and Bruno Jullien, 2018, Mergers, Investments and Demand Expansion, Economics Letters, 167, 136-41

Bourreau, Marc, Bruno Jullien and Yassine Lefouili, 2018, Mergers and DemandEnhancing Innovation, mimeo, Toulouse School of Economics

Chen, Zhijun and Patrick Rey, 2015, A Theory of Conglomerate Mergers, mimeo, Toulouse School of Economics

Choi, Jay Pil, 2008, Mergers with Bundling in Complementary Markets, Journal of Industrial Economics, 56, 3, 553-577

Choi, Jay Pil and Doh-Shin Jeon, 2016, A Leverage Theory of Tying in TwoSided Markets, CEPR dp 11484

Choi, Jay Pil and Christodoulos Stefanadis, 2001, Tying, Investment, and the Dynamic Leverage Theory, The RAND Journal of Economics, 32, 1, 52-71

Czarnitzki, Dirk, Federico Etro and Kornelius Kraft, 2014, Endogenous Market Structures and Innovation by Leaders: an Empirical Test, Economica, 81, 321, 117-139

Davidson, Carl and Ben Ferrett, 2007, Mergers in Multidimensional Competition, Economica, 74, 695-712

Davidson, Carl and Arijit Mukherjee, 2007, Horizontal Mergers with Free Entry, International Journal of Industrial Organization, 25, 1, 157-72

Deneckere, Raymond and Carl Davidson, 1985, Incentives to form Coalitions with Bertrand Competition, The RAND Journal of Economics, 16, 4, 473-86

Denicolò, Vincenzo, 2000, Compatibility and Bundling with Generalist and Specialist Firms, Journal of Industrial Economics, 48, 2, 177-88

Denicolò, Vincenzo and Michele Polo, 2018, Duplicative Research, Mergers and Innovation, Economics Letters, 166, 56-59

Economides, Nicholas and Steven Salop, 1992, Competition and Integration among Complements, and Network Market Structure, Journal of Industrial Economics, 40, 1, 105-23

Etro, Federico, 2007, Competition, Innovation, and Antitrust, New York: Springer 
Etro, Federico, 2018, Conglomerate Mergers and Entry in Innovative Industries, WP 2018:19, Ca' Foscari University, Venice

Etro, Federico and Cristina Caffarra, 2017, On the Economics of the Android Case, European Competition Journal, 13, 2-3, 282-313

Federico, Giulio, Gregor Langus and Tommaso Valletti, 2017, A Simple Model of Mergers and Innovation, Economics Letters, 157, August, 136-140

Federico, Giulio, Gregor Langus and Tommaso Valletti, 2018, Horizontal Mergers and Product Innovation: An Economic Framework, International Journal of Industrial Organization, 59, July, 1-23

Fumagalli, Chiara, Massimo Motta, Claudio Calcagno, 2018, Exclusionary Practices. The Economics of Monopolisation and Abuse of Dominance, Cambridge: Cambridge University Press

Gilbert, Richard and Hillary Greene, 2015, Merging Innovation into Antitrust Agency Enforcement of the Clayton Act, George Washington Law Review, $83,6,1919-1947$

Hurkens, Sjaak Doh-Shin Jeon and Domenico Menicucci, 2019, Dominance and Competitive Bundling, American Economic Journal: Microeconomics, in press

Jullien, Bruno and Yassine Lefouili, 2018, Horizontal Mergers and Innovation, Journal of Competition Law and Economics, 14, 3, 364-392

Llobet, Gerard and Jorge Padilla, 2017, The Inverse Cournot Effect in Royalty Negotiations with Complementary, mimeo, CEMFI

Lopez, Angel and Xavier Vives, 2016, Cross-ownership, R\&D Spillovers, and Antitrust Policy, CESifo WP No.5935

Marshall, Guillermo and Alvaro Parra, 2018, Innovation and Competition: The Role of the Product Market, mimeo, University of Illinois at Urbana-Champaign

Matsushima, Noriaki, Yasuhiro Sato and Kazuhiro Yamamoto, 2013, Horizontal Mergers, Firm Heterogeneity, and R\&D Investments, The B.E. Journal of Economic Analysis \& Policy, 13, 2, 959-90

Matutes, Carmen and Pierre Regibeau, 1992, Compatibility and Bundling of Complementary Goods in a Duopoly, Journal of Industrial Economics, 40, 1, $37-54$

Motta, Massimo, 2004, Competition Policy. Theory and Practice, Cambridge: Cambridge University Press

Motta, Massimo and Emanuele Tarantino, 2016, The Effect of a Merger on Investments, CEPR DP11550

Nocke, Volker and Nicolas Schutz, 2018, Multiproduct-Firm Oligopoly: An Aggregative Games Approach, Econometrica, 86, 2, 523-557.

Sah, Raaj Kumar and Joseph E. Stiglitz, 1987, The Invariance of Market Innovation to the Number of Firms, The RAND Journal of Economics, 18, 1, 98-108.

Salant, Stephen W., Sheldon Switzer and Robert Reynolds, 1983, Losses from Horizontal Merger: the effects of an exogenous change in industry structure on Cournot-Nash equilibrium, Quarterly Journal of Economics, 98, 2, 185199 
Salinger, Michael, 2016, Net Innovation Pressure in Merger Analysis, mimeo, Boston University

Schmutzler, Armin, 2013, Competition and Investment. A unified approach, International Journal of Industrial Organization, 31, 477-87.

Shapiro, Carl, 2012, Competition and Innovation. Did Arrow hit the bull's eye?, Ch. 7 in The Rate and Direction of Inventive Activity Revisited, Josh Lerner and Scott Stern Eds, 361-404

\section{APPENDIX}

Proof of Proposition 1. Consider the innovation game post-merger. The investment in each component for the merged firm is selected to maximize the joint profits:

$$
\begin{aligned}
\mathbb{E}\left(\pi_{M}\right)= & \left(1-z_{A}\right)\left(1-z_{B}\right)\left(1-c_{A}-c_{B}\right)+\left(1-z_{A}\right) z_{B}\left(1-\lambda c_{B}-c_{A}\right) \\
& +\left(1-z_{B}\right) z_{A}\left(1-\lambda c_{A}-c_{B}\right)-I\left(\bar{c}-c_{A}\right)-I\left(\bar{c}-c_{B}\right)
\end{aligned}
$$

with FOCs:

$$
\left(1-z_{i}\right)\left(1-z_{j}\right)+\left(1-z_{i}\right) z_{j}+\lambda\left(1-z_{j}\right) z_{i}=I^{\prime}\left(\bar{c}-c_{i}\right) \text { for } i, j=A, B
$$

The new terms on the left hand side show that the merger fixes the Cournot complementarity problem, increasing the investment of the incumbents. Indeed, in a symmetric equilibrium I have $(1-z)(1+\lambda z)=I^{\prime}(\bar{c}-c)$. The left hand side of this equation is higher than in the pre-merger condition $\frac{1-z^{2}}{2}=I^{\prime}(\bar{c}-c)$ and always decreasing in the investment of the entrants. Since the FOCs of the entrants are the same as before, I can solve for the same investment rule of the entrants, with $z^{M}=z\left(\lambda, c^{M}\right)$ where $c^{M}$ satisfies equation (11) in the text. The marginal benefit of $\mathrm{R} \& \mathrm{D}$ ranges between 1 under full price squeeze $(\lambda \rightarrow 0)$ and $1-\left(c^{M}\right)^{2}$ when the entrant can extract the entire surplus of its innovation $(\lambda=1)$. Under full price squeeze $z^{M}=0$, and when the entrant can extract the entire surplus $z^{M}=c^{M}$.

The expected profits for the merged firms are $\mathbb{E}\left(\pi_{M}\right)=\mathbb{E}\left(\pi_{J}\left(c^{M}\right)\right)$, where the function $\mathbb{E}\left(\pi_{J}(c)\right)$ is defined by (8), and they must increase compared to the pre-merger situation because the merger delivers coordination of $\mathrm{R} \& \mathrm{D}$. The expected profits are again a continuous and non-monotonic function of $\lambda$ because a low $\lambda$ allows the merged firm to appropriate most of the surplus created by each single entrant but disincentivizes its innovation, and a high $\lambda$ increases the probability of innovations but leaves most of the rents to the entrants, while an intermediate $\lambda$ generates higher expected profits. In any case, since $z\left(\lambda, c^{M}\right)<z(\lambda, c)$, the merger reduces always the investment of the entrants and therefore the probability of a price reduction. Expected consumer surplus becomes:

$$
\mathbb{E}\left(C S\left(c^{M}\right)\right)=\frac{\left(\lambda c^{M}\right)^{2}\left(1-2 c^{M}\right)}{\left[1-c^{M}(1-\lambda)\right]^{2}}
$$

Remembering that $\mathbb{E}(C S(c))$ is an inverse-U shaped function, the merger reduces consumer surplus $\mathbb{E}\left(C S\left(c^{M}\right)\right)$ whenever the incumbents are efficient enough 
before the merger: this happens always for $\bar{c}<\hat{c}(\lambda)$, but a weaker condition is that the marginal cost pre-merger is below the "golden rule" level $\hat{c}(\lambda)$

Proof of Proposition 2. Consider the innovation game under a merger with bundling. The expected profits of the merged entity are:

$$
\mathbb{E}\left(\pi_{M}^{B}\right)=\left(1-z_{A} z_{B}\right)\left(1-c_{A}-c_{B}\right)-I\left(\bar{c}-c_{A}\right)-I\left(\bar{c}-c_{B}\right)
$$

and the expected profits of the entrant producing component $i, j=A, B$ are:

$$
\pi_{i}^{e}=z_{i} z_{j} c_{i}-\frac{z_{i}^{2}}{2}
$$

Under simultaneous investments, the FOCs of the incumbents are $1-z_{i} z_{j}=$ $I^{\prime}\left(\bar{c}-c_{i}\right)$ for $i, j=A, B$, and the FOCs of the entrants are $z_{i}=z_{j} c_{i}$ for $i, j=A, B$. The only Nash equilibrium satisfies:

$$
1=I^{\prime}\left(\bar{c}-c^{B}\right) \quad \text { and } z^{B}=0 .
$$

The profits of the merged entity are:

$$
\pi_{M}^{B}=1-2 c^{B}-2 I\left(\bar{c}-c^{B}\right)
$$

which is independent from the degree of price squeeze. It is immediate to verify that pure bundling weakly increases joint profits compared to the pre-merger situation for $\lambda=0$ and increases them for $\lambda=1$, but it does not necessarily increase profits for intermediate values of $\lambda$ when the incumbents are relatively inefficient before the merger: this is indeed the case where the merger without bundling optimizes the trade-off between appropriating the rents of a single innovator and leaving enough incentives to the same entrants to invest.

The comparison of the profits with and without pure bundling is now straightforward. With a full price squeeze $(\lambda \rightarrow 0)$ I obtain $c^{M}=c^{B}$ and zero investment by the entrants in both regimes, therefore the expected profits is the same with or without bundling: $\mathbb{E}\left(\pi_{M}\right)=\pi_{M}^{B}$. When the entrant can extract the entire surplus of its innovation $(\lambda=1)$, I have $z^{M}=c^{M}>c^{B}$ and:

$$
\mathbb{E}\left(\pi_{M}\right)=\left(1-\left(c^{M}\right)^{2}\right)\left(1-2 c^{M}\right)-2 I\left(\bar{c}-c^{M}\right)<1-2 c^{M}-2 I\left(\bar{c}-c^{M}\right)<\pi_{M}^{B}
$$

since $c^{B}$ maximizes $1-2 c-2 I(\bar{c}-c)$. Nevertheless, for low levels of $\lambda$ and high levels of $c^{M}$, a merger without pure bundling must be superior because it allows the merged firm to extract some of the surplus created by the entrants, which is useful when the incumbents are not very efficient. Therefore, by continuity, a commitment to pure bundling for the merged entity is profitable at least when $\lambda$ is high enough

Proof of Proposition 3. Let us consider a general cost function for the investment of the entrants, $F(z)$ with $F^{\prime}(z)>0, F^{\prime \prime}(z)>0, F(0)=F^{\prime}(0)=0$ 
and $F^{\prime}(1) \geq \bar{c}$. Following the same steps as in the baseline model, in the premerger situation one can obtain a symmetric equilibrium where the strategies of the incumbents and the entrants satisfy the following relations:

$$
\frac{1-z^{2}}{2}=I^{\prime}(\bar{c}-c) \quad \text { and } \quad F^{\prime}(z)=z c+(1-z) \lambda c
$$

The first condition provides a continuous function expressing the marginal cost of the incumbents in function of the probability of innovation of the entrants:

$$
c(z)=\bar{c}-I^{\prime-1}\left(\frac{1-z^{2}}{2}\right) \quad \text { with } c^{\prime}(z)=\frac{z}{I^{\prime \prime}(\bar{c}-c(z))}>0
$$

where $c(0) \geqslant 0$ and $c(1)=\bar{c}$ (convexity holds if $\left.I^{\prime \prime \prime} \geq 0\right)$. The second condition defines another continuous function $z(\lambda, c)$ if the technology is convex enough, namely if the elasticity of the marginal cost $\sigma(z) \equiv F^{\prime \prime}(z) z / F^{\prime}(z)$ is larger than $[1+\lambda /(1-\lambda) z]^{-1}$ for any $\lambda$, as I will assume. Inverting it, allows me to define a second relation in the space $(z, c)$ as:

$$
C(z)=\frac{F^{\prime}(z)}{z(1-\lambda)+\lambda} \quad \text { with } C^{\prime}(z)=\frac{C(z)}{F^{\prime}(z)}\left[F^{\prime \prime}(z)-(1-\lambda) C(z)\right]>0
$$

where $C(0)=0$ and $C(1)>\bar{c}$, and the sign of the derivative relies on the assumption of convexity (which was always satisfied in the quadratic example where $\sigma(z)=1$ ). These conditions are sufficient to insure that the two functions cross at an equilibrium $c(z)=C(z) \in[0, \bar{c}]$, which is assumed to be unique for any $\lambda .^{27}$ Since the probability of innovation derived from the optimality conditions of the entrants, $z(\lambda, c)$, is still increasing in $c$ under our assumptons, consumer surplus:

$$
\mathbb{E}(C S(c))=z(\lambda, c)^{2}(1-2 c)
$$

remains an inverse- $U$ shaped function of the marginal cost for $c \in[0,0.5]$.

In the post-merger situation the equilibrium strategies of the incumbents and the entrants satisfy the following relations:

$$
(1-z)(1+\lambda z)=I^{\prime}(\bar{c}-c) \text { and } \quad F^{\prime}(z)=z c+(1-z) \lambda c
$$

and the only difference compared to the case above is that the post-merger function $c(z)=\bar{c}-I^{\prime-1}[(1-z)(1+\lambda z)]$ is strictly below the pre-merger function for any $z$. This confirms the increase in investment for the incumbents after the merger and the reduction of investment for the entrants. As in the baseline model, the merger must be profitable and it reduces consumer surplus if the merging firms are already efficient enough before the merger (because, in such a case, it acts on the upward sloping side of the $\mathbb{E}(C S(c))$ function).

\footnotetext{
${ }^{27}$ Unicity requires additional conditions on the shape of the technology, insuring $c^{\prime}(z)<$ $C^{\prime}(z)$ in equilibrium for any $\lambda$. With our quadratic specifications, $c(z)=1 / 2-\left(1-z^{2}\right) / 4 \beta$ is convex, $C(z)=z /[z(1-\lambda)+\lambda]$ is convex if and only if $z<\lambda /(1-\lambda)$, and the interior equilibrium is unique for any $\beta>1 / 2$.
} 
In case of pure bundling the equilibrium strategies satisfy the new symmetric optimality conditions:

$$
1-z^{2}=I^{\prime}(\bar{c}-c) \quad \text { and } \quad F^{\prime}(z)=z c
$$

The first one delivers a function $c(z)=\bar{c}-I^{\prime-1}\left(1-z^{2}\right)$ which is weakly below the corresponding one for the merger without bundling for any $z$. The second condition confirms immediately the existence of an equilibrium with $z^{B}=0$ and $c^{B}=c(0)$ with the same implications as in the baseline model. However, when $C(z)=F^{\prime}(z) / z$ is increasing, which requires a cost function convex enough that $\sigma(z)>1$, I obtain another equilibrium with positive investment by the entrants satisfying:

$$
1-z^{B 2}=I^{\prime}\left[\bar{c}-\frac{F^{\prime}\left(z^{B}\right)}{z^{B}}\right]
$$

Remarkably, also such an equilibrium implies less investment by the entrants and more by the incumbents compared to the pre-merger situation. Therefore a commitment to bundling can still be profitable and reduce consumers surplus.

For instance, consider a cost function $F(z)=\phi \frac{z^{1+\sigma}}{1+\sigma}$ where $\phi>1 / 2$ parameterizes the marginal cost of $\mathrm{R} \& \mathrm{D}$ for the entrants and $\sigma>0$ is the constant elasticity of the marginal cost, and assume $\lambda=1$. Before the merger, the equilibrium relation for the entrants delivers $z=(c / \phi)^{\frac{1}{\sigma}}$, which is decreasing in the difficulty of entry $\phi$ and increasing in the marginal cost of the incumbents. A merger without bundling reduces the latter and the probability of entry as usual. A merger with pure bundling generates an equilibrium with $z^{B}=0$ as before. But when $\sigma>1$, there is also another equilibrium with $z^{B}=\left(c^{B} / \phi\right)^{\frac{1}{\sigma-1}}<(c / \phi)^{\frac{1}{\sigma}}$ (since $c^{B}<c<\phi$ ), therefore the probability of entry is reduced further by bundling, but not eliminated in this case

Proof of Proposition 4. Under a linear demand, before the merger the expected profits of the incumbents producing component $i, j=A, B$ become:

$$
\mathbb{E}\left(\pi_{i}\right)=\left(1-z_{i}\right)\left(1-z_{j}\right) \frac{\left(1-c_{i}-c_{j}\right)^{2}}{9}+\left(1-z_{i}\right) z_{j} \frac{\left(1-c_{i}-c_{j}\right)^{2}}{4}-I\left(\bar{c}-c_{i}\right)
$$

and the expected profits of the entrants in component $i, j=A, B$ are:

$$
\mathbb{E}\left(\pi_{i}^{e}\right)=z_{i} z_{j}\left(1-c_{i}-c_{j}\right) c_{i}+z_{i}\left(1-z_{j}\right) \frac{\left(1-c_{i}-c_{j}\right) c_{i}}{2}-\frac{z_{i}^{2}}{2}
$$

The best response functions exhibit strategic complementarity not only between the entrants, but also between the incumbents: a higher investment by an incumbent (an entrant) induces the other incumbent (entrant) to invest more as well. Under simultaneous choices and symmetry, the probability of innovation of the entrants can be derived as:

$$
z(c)=\frac{c(1-2 c)}{2-c(1-2 c)}
$$


which is an increasing function of the marginal cost of the incumbents in the relevant range $\left(z^{\prime}(c)>0\right)$ due to the assumption that the innovations of the entrants are not drastic (notice that this requires $c<1 / 4$ ): the entrants invest less when the marginal cost of the incumbents decreases as in the baseline model.

The FOCs of the incumbents in a symmetric equilibrium become:

$$
\frac{(1-2 c)(1-z)(4+5 z)}{18}=I^{\prime}(\bar{c}-c)
$$

The left hand side is increasing in the investment of the entrants in the relevant range $\left(c^{\prime}(z)<0\right)$ : this result differs from the baseline model and it is due to the substantial increase in profits for the incumbents when the non-competing entrant innovates. Clearly, one can use both conditions to obtain a unique equation for the pre-merger value of the marginal cost of the incumbents and derive therefore the equilibrium probability of innovation, but this is not necessary for our subsequent comparisons. In the pre-merger situation the joint profits of the incumbents can be computed as:

$$
\mathbb{E}\left(\pi_{J}\right)=\frac{\left[4+z(c)-5 z(c)^{2}\right](1-2 c)^{2}}{18}-2 I(\bar{c}-c)
$$

The expected consumer surplus is a weighted average of consumer surplus in the four states of the world, and can be simplified as:

$$
\mathbb{E}(C S(c))=\frac{\left[2+5 z(c)+11 z(c)^{2}\right](1-2 c)^{2}}{36}
$$

which is a strictly positive and non-monotonic function of $c$, to be evaluated at the equilibrium marginal cost characterized above.

I now move to consider the merger without bundling. The expected profits of the merged firm become:

$$
\mathbb{E}\left(\pi_{M}\right)=\left(1-z_{i} z_{j}\right) \frac{\left(1-c_{i}-c_{j}\right)^{2}}{4}-I\left(\bar{c}-c_{j}\right)-I\left(\bar{c}-c_{i}\right)
$$

The optimality conditions of the entrants are the same as before, while the equilibrium condition for the investment of the merged firm becomes:

$$
\frac{\left(1-2 c^{M}\right)\left(1-z^{2}\right)}{2}=I^{\prime}\left(\bar{c}-c^{M}\right)
$$

whose left hand side, representing the marginal benefit of investment, is always larger than the corresponding expression pre-merger. This clearly implies that the merger induces the incumbents to invest more and set lower prices, and it also means that the merger is always profitable with expected profits:

$$
\mathbb{E}\left(\pi_{M}\right)=\frac{\left[1-z\left(c^{M}\right)^{2}\right]\left(1-2 c^{M}\right)^{2}}{4}-2 I\left(\bar{c}-c^{M}\right)
$$

Under our assumptions it also implies that the investment of the entrants must decrease post-merger. The expected consumer surplus can be computed as:

$$
\mathbb{E}\left(C S_{M}\left(c^{M}\right)\right)=\frac{\left[1+3 z\left(c^{M}\right)^{2}\right]\left(1-2 c^{M}\right)^{2}}{8}
$$


which is again an inverse- $\mathrm{U}$ shaped function of the marginal $\operatorname{cost} c^{M}$ with $\mathbb{E}\left(C S_{M}(c)\right)>\mathbb{E}(C S(c))$ for any possible $c$. The first implication is that without investment by the incumbents, i.e. $c=c^{M}=\bar{c}$, the merger increases always consumer surplus. If there is endogenous investment by the incumbents, the merger tends to benefit consumers when the incumbents are inefficient, because the interest of incumbents and consumers in reducing costs are aligned: the gains from reducing high prices in all states of the world are large and the losses from reducing the probability of joint entry (with prices below those of other states of the world) are small. The merger could harm consumers only if the incumbents are initially efficient enough. However, this is now a necessary condition, but not a sufficient one, because the merger must also induce a large enough reduction in the probability of innovation (a large enough $c^{M}-c$ ) for consumer surplus to decrease in expected terms. While the extent of this cost reduction depends on the $R \& D$ technology of the incumbents, the numerical computation shows that such an anti-competitive outcome cannot occur under our linear demand model.

Finally, let us consider the possibility of a credible commitment to adopt pure bundling after the merger. This delivers the following expected profits for the merged firm:

$$
\mathbb{E}\left(\pi_{M}^{B}\right)=\left(1-z_{i} z_{j}\right) \frac{\left(1-c_{i}-c_{j}\right)^{2}}{4}-I\left(\bar{c}-c_{i}\right)-I\left(\bar{c}-c_{j}\right)
$$

while the profits of the entrants become:

$$
\mathbb{E}\left(\pi_{i}^{e}\right)=z_{i} z_{j}\left(1-c_{i}-c_{j}\right) c_{i}-\frac{z_{i}^{2}}{2}
$$

It is immediate to derive the unique Nash equilibrium with:

$$
\frac{1}{2}-c^{B}=I^{\prime}\left(\bar{c}-c^{B}\right) \quad \text { and } \quad z^{B}=0
$$

Once again bundling induces entry deterrence and increases the investment of the incumbents beyond the case of a baseline merger. Notice that the profits of the merged firm are $\pi_{M}^{B}=\frac{\left(1-2 c^{B}\right)^{2}}{4}-2 I\left(\bar{c}-c^{B}\right)$, which is necessarily above the profits from the merger without bundling. Therefore, when a commitment to bundling is feasible, it is always optimal to adopt it. Expected consumer surplus is simply:

$$
C S_{M}^{B}\left(c^{B}\right)=\frac{\left(1-2 c^{B}\right)^{2}}{8}
$$

It is now immediate to verify that $\mathbb{E}\left(\pi_{J}\right)<\mathbb{E}\left(\pi_{M}\right)<\pi_{M}^{B}$ and $\mathbb{E}\left(C S_{M}(c)\right)>$ $C S_{M}^{B}\left(c^{B}\right)>\mathbb{E}_{(}(C S(c))$. This confirms that pure bundling is always adopted for entry deterrence purposes when possible. It also follows that a merger with bundling reduces consumer surplus compared to a merger without bundling. However, the merger with bundling cannot make consumers worse off compared to the pre-merger situation, because it leads to a large enough price reduction. 
Of course, when the commitment to bundling is not credible, the merger takes place without it and consumers are again better off

Proof of Proposition 5. Consider the case where $\gamma>0$. In the pre-merger situation, the Nash equilibrium of the innovation game implies the endogenous probability of innovation:

$$
z(c)=\frac{\left(\frac{\gamma}{\gamma+1}\right)^{\gamma} c(1-2 c)^{\gamma}}{1-c(1-2 c)^{\gamma}\left[1-\left(\frac{\gamma}{\gamma+1}\right)^{\gamma}\right]}
$$

Before the merger, the equilibrium condition for the investment of the incumbents can be expressed as follows:

$$
\Psi(c)(1-z(c))\left\{1+z(c)\left[\left(\frac{\gamma+1}{\gamma+2}\right)^{\gamma+1}-1\right]\right\}=I^{\prime}(\bar{c}-c)
$$

where $\Psi(c) \equiv\left(\frac{\gamma(1-2 c)}{\gamma+1}\right)^{\gamma}$. Given this, the expected consumer surplus can be computed as:

$$
\mathbb{E}(C S(c))=\left[\frac{(1-z(c))^{2} \gamma^{\gamma+1}}{(\gamma+1)(\gamma+2)^{\gamma+1}}+\frac{z(c)^{2}}{\gamma+1}+\frac{2 z(c)(1-z(c)) \gamma^{\gamma+1}}{(\gamma+1)^{\gamma+2}}\right](1-2 c)^{\gamma+1}
$$

After a merger without bundling the innovation rule for the entrants is unchanged but the investment of the incumbents satisfies:

$$
\Psi\left(c^{M}\right)\left(1-z\left(c^{M}\right)^{2}\right)=I^{\prime}\left(\bar{c}-c^{M}\right)
$$

implying lower marginal costs and higher profits, with expected consumer surplus:

$$
\mathbb{E}\left(C S_{M}(c)\right)=\frac{\gamma^{\gamma+1}(1-2 c)^{\gamma+1}}{(\gamma+1)^{\gamma+2}}\left[1+z(c)^{2}\left[\left(\frac{\gamma+1}{\gamma}\right)^{\gamma+1}-1\right]\right]
$$

In case of bundling the equilibrium delivers as usual $z^{B}=0$ and:

$$
\Psi\left(c^{B}\right)=I^{\prime}\left(\bar{c}-c^{B}\right)
$$

with lower marginal costs, higher profits and lower consumer surplus compared to the merger without bundling:

$$
C S_{M}^{B}(c)=\frac{\gamma^{\gamma+1}(1-2 c)^{\gamma+1}}{(\gamma+1)^{\gamma+2}}
$$

To verify the impact of the merger on consumers, let us consider the simpler case where the incumbents do not invest $(c=\bar{c})$ but can commit to bundling. The identity $\mathbb{E}(C S(\bar{c}))=C S_{M}^{B}(\bar{c})$ defines implicitly a cut-off $\hat{\gamma}$ such that the 
merger harms consumers for any $\gamma \in[0, \hat{\gamma})$ and benefits them for $\gamma>\hat{\gamma}$. For instance, the cut-off can be directly computed as $\hat{\gamma} \approx 0.02$ when $\bar{c}=0.1, \hat{\gamma} \approx 0.08$ when $\bar{c}=0.2$ and $\hat{\gamma} \approx 0.17$ when $\bar{c}=0.3$.

Allowing for a positive investment by the incumbents preserves the optimality of the merger and of bundling. Of course, the set of parameter values under which the merger is pro- or anti-competitive changes with the cost reduction technology. Adopting a quadratic cost function $I(\bar{c}-c)=\beta(1 / 2-c)^{2}$ with $\beta>0$ parametrizing the difficulty of deterministic innovation, I can find a cutoff parameter $\hat{\gamma}(\beta)$ for which the merger is neutral on consumer surplus (such that $\hat{\gamma}(\infty)=\hat{\gamma}$ as in the earlier example). This cut-off is decreasing in $\beta$, and the space $(\beta, \gamma)$ can be divided in a low- $\gamma$ and high- $\beta$ region where the merger is anti-competitive, because it generates low gains from the internalization of price and $\mathrm{R} \& \mathrm{D}$ complementarities between incumbents and large losses from entry foreclosure, and a complementary region with high- $\gamma$ and low- $\beta$ where the merger is either neutral or pro-competitive because consumers can appropriate large benefits from cost and price reductions 